\title{
CHARACTERIZATION OF BITUMEN BINDERS ON THE BASIS OF THEIR THERMO-VISCOUS PROPERTIES
}

\author{
Michal HOLÝ1* Eva REMIŠOVÁ
}

\begin{abstract}
Bitumen is one of the basic building materials that is mainly used in road construction. Nowadays, we can observe increased requirements for the quality of bituminous binders, which are due to increased traffic loads, changing climate conditions, and decreasing crude oil stocks. Besides "traditional" (empirical) tests (softening point, penetration), new types of tests have been developed that can better describe the quality and behavior of bitumen binders. Their composition can also be a significant part of the properties themselves. Therefore, the elemental and group composition of bitumen must also be observed. The use of the viscosity temperature susceptibility (VTS) test appears to be well suited to evaluate the properties of bitumen binders. The VTS parameter is directly dependent on the viscosity of bitumen, but it is necessary to say that VTS can be significantly affected by the composition of the bitumen. The paper is focused on determining the dependencies between the VTS and the bitumen's composition, respectively, to find out how the composition influences the VTS.
\end{abstract}

\section{INTRODUCTION}

Bitumen is a complex of high-boiling or non-boiling components. These components do not change during the distillation process of crude oil, which is the reason they are still present in bitumen in their original unaltered form as in crude oil. Therefore, bitumen, like crude oil, is a natural product. As far as its chemical composition is concerned, we must realize that for any type of bitumen, as with any type of crude oil, we do not yet know completely know it. This can be explained by the fact that each type of bitumen is composed of a large number of different groups of hydrocarbons that have an average molecular weight of 600 to $1000 \mathrm{~g} / \mathrm{mol}$ as well as a relatively high proportion of non-hydrocarbons.

Bitumen is a complex chemical mixture of molecules that are predominantly hydrocarbons (carbon: 82 to $88 \%$, hydrogen: 8 to $11 \%$ ) with a small amount of structurally heterocyclic species and functional groups containing sulfur, nitrogen, and oxygen atoms. Bitumen

\section{Address}

1 Dept. of Highway Engineering, Faculty of Civil Engineering, University of Zilina, Zilina, Slovakia

* Corresponding author: michal.holy@fstav.uniza.sk

\section{Key words}

- Viscosity temperature susceptibility;

- Bitumen;

- Bitumen composition;

- Empirical tests. also contains minor quantities of metals such as vanadium, nickel, iron, magnesium, and calcium, which occur in the form of inorganic salts and oxides or in porphyrin structures.

The chemical composition of bitumen is extremely complex. Thus, a complete analysis of bitumen (if it were possible) would be extremely difficult and would produce such a large quantity of data that any correlation with its rheological properties would be impractical, if not impossible. However, it is possible to separate bitumen into two broad chemical groups called asphaltenes and maltenes as shown in (Nicholls, 1998; Read and Whiteoak, 2003). Maltenes can be further subdivided into saturates, aromatics, and resins (SARA). The four groups are not well defined, and there is some overlap between the two main divisions. Based on the precipitation from lower alkali hydrocarbons, saturated compounds can be included together with aromatics and resins in the malten phase and asphaltenes in the asphalt phase (Fig. 1). Asphaltenes can be considered as solid particles that thicken bitumen binders. They have a dark brown or 


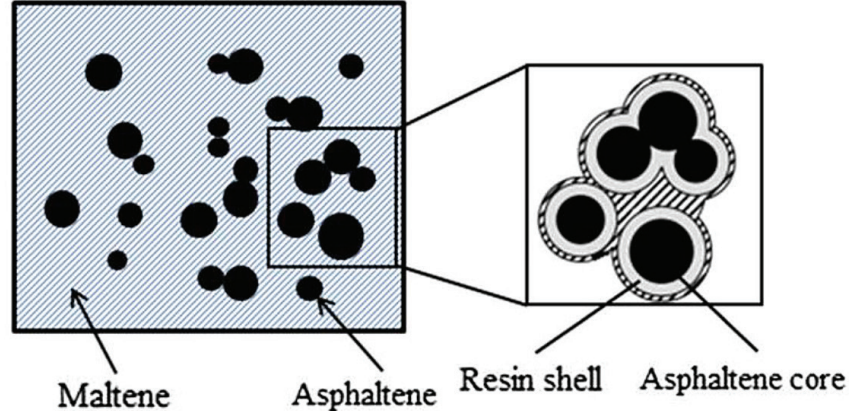

Fig. 1 Schematic diagram of the colloidal structure of a bitumen (Nicholls, 1998)

sometimes a black color and a higher molecular weight compared to resins. Asphaltenes can be characterized as aromatic and chlorinated solvents and also as insoluble in low boiling alkanes. Resins can be described either as highly viscous liquids or solids of a reddish-brown color. It can be stated that asphaltenes are the most important parts of bitumen binders that are dispersed in maltenes and that the resin has a significant effect on the stability of the asphaltenes that are dispersed in the resin. Bitumen from different sources of crude oil has different amounts of constituents and possibly different abilities to react, and each manifestation of a change in the behavior of bitumen (such as aging, etc.) is due to the inter-conversion of one type of constituent to another type.

Currently, the producers of asphalt mixtures use their own technological processes for improving their quality and ensuring the required applicability of the products. The required quality is achieved by ensuring the quality of the materials input, i.e., coarse and fine aggregates and bitumen. The properties of the bitumen are verified by prescribed tests, which the bitumen binder must satisfy and which are critical to the designation and definition of bitumen binders. The criteria for the quality of the bitumen are defined in EU standards and in Slovakia in catalog sheets for bitumen (CASB, 2014). The datasheets determine how to use bitumen binders for the production of mixtures for wearing and base courses and binders.

The quality of the bitumen binders used in the construction and maintenance of road pavements is currently being assessed by empirical tests that were designed around 100 years ago and are based on obtaining one value for specific boundary conditions. The consistency of the binders at medium service temperatures (penetration), increased service temperatures (the softening point), and lower temperatures (the breaking point) is measured, regardless of the composition of the bitumen and the loads corresponding to actual loads on a road. Research work on bituminous binders and asphalt mixtures was based on the assumption that empirical tests could characterize and classify but not accurately describe the properties of bitumen binders as viscoelastic materials. The current state of asphalt roads has led to new methods and approaches being sought to better describe the properties of bitumen binders and mixtures. One such approach is the "performance-related" approach (Read and Whiteoak, 2003; Shafiq, 2016). The system mainly evaluates bitumen binders by thermal stability tests (short-term RTFOT and long-term PAV) and functional tests that determinine the stiffness modules using a dynamic rheometer (DSR) and a deflection beam rheometer (BBR). Bitumen binders are tested not in the state in which they leave a refinery, but in the state in which they leave an asphalt mixing plant or after a certain period of exposure in service on a road (Fig. 2). Primary emphasis is given to the characterization of their rheological behaviour, i.e., viscoelastic behaviour, as a function of the temperature and loading rate. The behavior of bitumen is primarily seen as a chemical composition

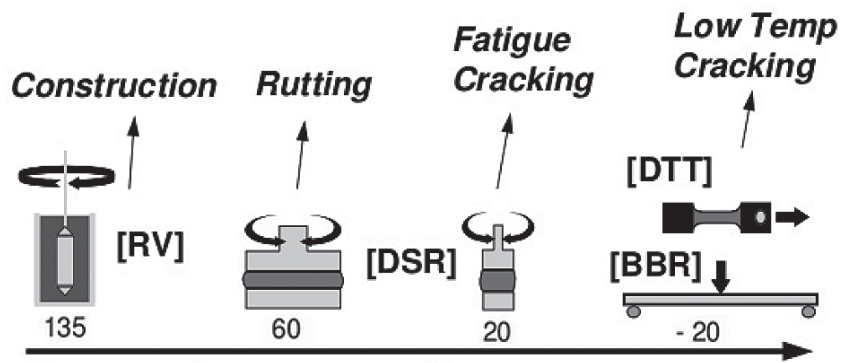

Pavement Temperature, $\mathrm{C}$

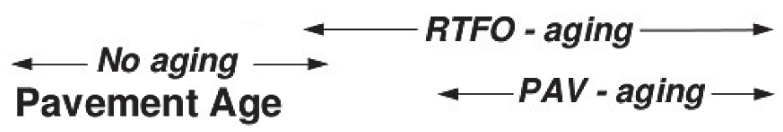

Fig. 2 Types of equipment and requirements for bituminous binders according to the performance-related approach (Shafiq, 2016)

that is influenced by the source of the petroleum and the processing method for the bitumen.

The main aim in the application of new procedures for determining functional characteristics is to become much better in assessing, evaluating, or optimizing bituminous binders. A description of the behaviour of bitumen is used in finished designs that best fits the actual conditions and takes into account factors such as temperature changes, load changes, or the overall load dynamics of road construction.

A bitumen binder is considered to be a relatively complex material, and a description of its properties is very demanding. To a great extent a functional approach emphasizes the rheology, which is an important aspect with respect to the viscoelastic nature of bitumen binders. The basic variable in rheology that characterizes the flow behavior of the material is viscosity, and one way of describing the properties of bitumen binders could be the use of viscosity. In recent years, due to progressive using of modified bitumen binders, most of research activities were focused on measuring of rheological and creep properties as a complex shear modulus. Within the scope of the SHRP program in the United States (Petersen, 1994) the visocisty was studied as performance-related specification to assess the optimal temperature of bitumen during mixing, laydown and compaction of asphalt mixtures. Therefore the paper is focused on thermo-viscous characterisation of bitumen binders. The research is rather focused on the possibility of reducing viscosity by various additives (Peilong and et al, 2018) and consequently reducing the working temperatures of WMA mixtures (Kataware and Singh, 2017).

\section{VISCOSITY-TEMPERATURE SUSCEPTIBILITY}

The temperature susceptibility of bitumen is characterized as a change in its consistency (viscosity or penetration of the bitumen) due to a change in temperature. In (Mallick and El-Korchi, 2009; EN 12591, 2009), three parameters can be used to determine the temperature susceptibility of bitumen, i.e., the penetration index (PI), the penvis number, and the viscosity-temperature susceptibility. The values of PI are calculated using the following equations:

$$
P I=\frac{20(1-25 \mathrm{~A})}{1+50 \mathrm{~A}}
$$

and

$$
A=\frac{\log p e n T_{1}-\log 800}{T_{1}-\mathrm{SP}}
$$

where pen $T_{l}$ is the penetration value at a temperature of $25^{\circ} \mathrm{C}$, and $S P$ is the temperature of the softening point. Higher values of PI indi- 


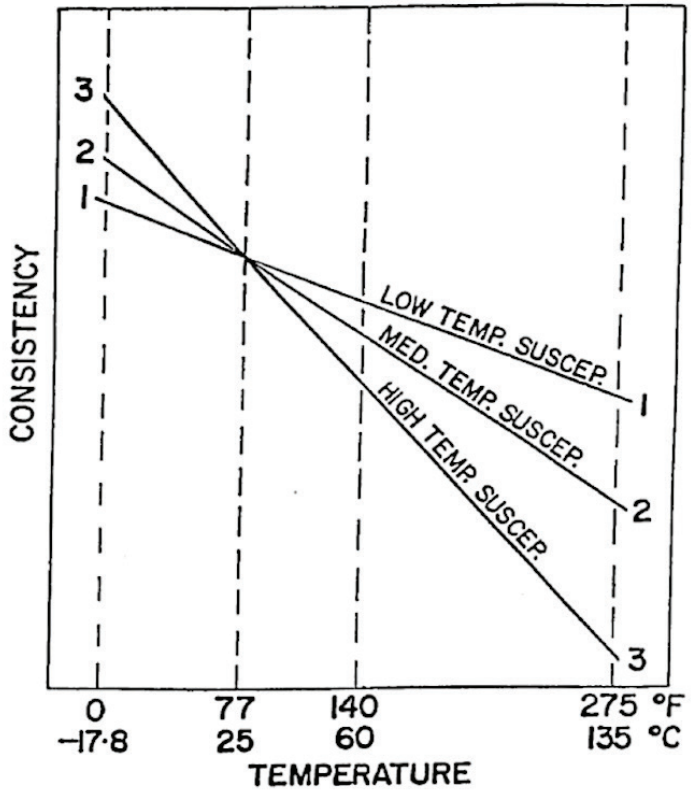

Fig. 3 Graph illustrating different temperature susceptibilities of paving bitumen (Mallick and El-Korchi, 2009)

cate a lower susceptibility to the temperature. The viscosity-temperature susceptibility parameter is determined from the relation between the viscosity values at a certain temperature. As shown in Figure 3 (ASTM D4402, 2016), a straight line graph results when the log-log viscosity of a bitumen is plotted versus the log of its absolute temperature. The slope of this line provides the temperature susceptibility of the bitumen. Figure 3 illustrates the temperature susceptibility of three bitumens, all of which have the same consistency at $25^{\circ} \mathrm{C}\left(77^{\circ} \mathrm{F}\right)$.

The viscosity-temperature susceptibility is determined as:

$$
V T S=\frac{\log \log \text { viscosity at } T_{2}-\log \log \text { viscostiy at } T_{1}}{\log T_{1}-\log T_{2}}
$$

The viscosity-temperature susceptibility (VTS) has been promoted by the Asphalt Institute (Mallick and El-Korchi, 2009) as a criterion for paving grade bitumen temperature susceptibility. In this approach, the VTS is based on the difference in the log log viscosity at each of two temperatures, usually $135^{\circ} \mathrm{C}\left(275^{\circ} \mathrm{F}\right)$ and $60{ }^{\circ} \mathrm{C}\left(140^{\circ}\right.$ F), which are divided by the difference in the logs of the same two absolute temperatures. This equation reduces temperature susceptibility to a very small number, since for example, the value of $\log \log 1000$ is only 0.4771 and only 0.4312 for 500 , with the difference between them only being 0.0459 . With such small numbers, the supporters of VTS, who refuse to admit that temperature susceptibility is an important property of paving bitumen, can argue that paving asphalt temperature susceptibility either does not exist, is not significant, or is merely the result of an experimental error.

\section{EXPERIMENTAL PROGRAM}

The aim of the experimental measurements was to determine the dependencies between the thermo-viscous and empirical properties (penetration and softening point) and the composition (group and elementary composition) of the bitumen. The purpose of the laboratory measurements was to study the properties of binders for the production of asphalt mixes that are commonly used in practice for asphalt pavement construction, i.e., paving grade bitumen 50/70 (6 samples from different producers, marked A1 - A6) and polymer-modified bitumen PMB 45/80-75 (5 samples from different producers, marked M1 - M5).

The viscosity-temperature susceptibility was determined by a dynamic viscosity data evaluation within a temperature range of $120^{\circ}$ to $180^{\circ} \mathrm{C}$. The dynamic viscosity measurements were performed according to EN 13302 using a Brookfield DV-II+PRO viscometer model with a cylindrical spindle. The empirical properties were determined by conducting the softening point (STN EN 1427, 2015) and penetration tests (STN EN 1426, 2016).

To realize an elementary analysis and determine the Carbon $(\mathrm{C})$, Hydrogen $(\mathrm{H})$, Nitrogen $(\mathrm{N})$ and Sulphur (S)content, an Elementar Vario Cube with TCD detection was used. The test was performed by means of a controlled sample combustion process at a temperature of 800 to $1000^{\circ} \mathrm{C}$ followed by an analysis of the flue gases by the detector. To determine the content of structurally similar compounds, a SARA analysis (determining the percentage of saturated hydrocarbons, aromatics, resins, and asphaltenes) was carried out using the combined extraction method and liquid chromatography. These procedures required special equipment and chemical agents (n-heptane, toluene, alumina $507 \mathrm{C}$ sorbent, silver nitrate modified silica gel) and specialized laboratories (VŠCHT, 2017). These analyses were carried out at the Institute of Oil and Alternative Fuels VŠCHT in Prague.

\section{RESULTS AND ANALYSIS}

The results from the tests of the empirical properties of the bitumen, which were based on a performance-related approach and composition analysis, are listed in subsequent sections of this paper. Table 1 shows the average values of the group and elementary compositions of the paving grade bitumen 50/70 (6 tested samples: A1 -A6) and the polymer-modified bitumen 45/80-75 (5 tested samples: M1 - M5). From the results of the chemical composition analysis,
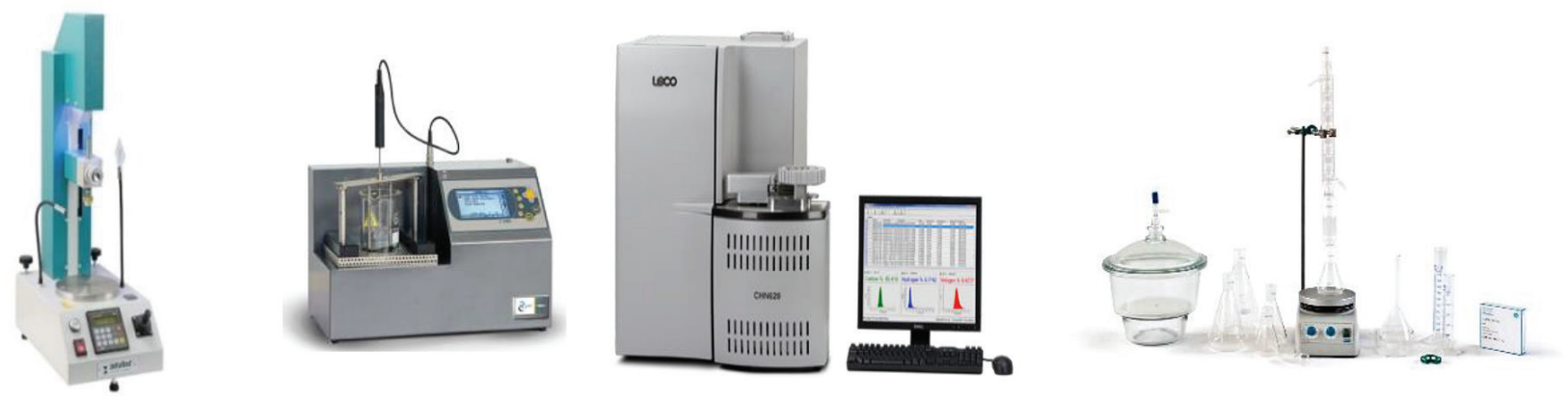

Fig. 4 Equipment for the tests performed (from the left: penetration, softening point, elementary analysis, group analysis) 
Tab. 1 Content of components in the bitumen samples tested

\begin{tabular}{|c|c|c|c|c|}
\hline \multicolumn{5}{|c|}{ Content of components in samples (\%) } \\
\hline Type of bitumen & Saturates & Aromatics & Resins & Asphaltenes \\
\hline $50 / 70$ & $6.17-10.09$ & $32.9-37.76$ & $39.09-48.24$ & $10.53-17.54$ \\
\hline Average 50/70 & 8.41 & 36.03 & 42.41 & 13.15 \\
\hline PMB 45/80-75 & $6.18-11.62$ & $33.03-34.71$ & $37.09-47.73$ & $12.52-15.02$ \\
\hline Average PMB 45/80-75 & 8.50 & 35.62 & 40.65 & 15.23 \\
\hline Type of bitumen & C & $\mathbf{H}$ & $\mathbf{N}$ & $\mathbf{S}$ \\
\hline $50 / 70$ & $82.7-85.29$ & $9.92-10.45$ & $0.371-0.712$ & $3.21-6.12$ \\
\hline Average 50/70 & 84.50 & 10.26 & 0.58 & 3.95 \\
\hline PMB 45/80-75 & $84.31-85.35$ & $10.15-10.39$ & $0.476-0.581$ & $2.99-4.72$ \\
\hline Average PMB 45/80-75 & 84.96 & 10.37 & 0.54 & 3.64 \\
\hline
\end{tabular}

it can be stated that the greatest difference is between the PMB and PG in the aromatics content (the PG has a $+1.76 \%$ higher content of aromatics compared to the $\mathrm{PMB}$ ) and asphaltenes (the PMBs have a $+2.08 \%$ higher content of asphaltenes compared to the PG). In the group composition we can see that the paving grade bitumen has higher values of aromatics and resins, while the polymer-modified bitumen has higher values of saturates and asphaltenes. From the point of view of the elemental composition, we can see that both types of bituminous binders have relatively the same nitrogen and hydrogen contents and that the differences can be observed in the carbon (the PMB has a $+0.46 \%$ higher $C$ content when compared to the $\mathrm{PG}$ ) and sulphur (the $\mathrm{PG}$ has a $+0.31 \%$ higher $\mathrm{S}$ content when compared to the PMB) content. Differences in the specific numerical values of the contents of the individual components are influenced by the origin of the crude oil itself as well as by the technological processes used in refineries in the production of bitumen binders.

As mentioned above, the quality of the bituminous binders was verified by empirical tests that are defined in the standards (EN 1426, 2010; EN 1427, 2010), or catalog sheets (CSAB, 2014), of bitumen binders. A "suitable" bitumen is a bitumen that meets the condition that the measurement value of the bitumen is either between two boundaries for PG bitumen (penetration or a softening point) or the value of the measured property is higher than the minimum limit (as is the case with the softening point of the PMB). The values from the measurements of the softening point and penetration of the bitumen binders tested are presented in Table 2. Despite using the same grade of bitumen, we can observe a relatively high degree of variability in the results. In the case of the paving grade bitumen, the range of the softening points is from $48^{\circ} \mathrm{C}$ to $51^{\circ} \mathrm{C}$, and the range of penetration is from 54.3 to $70.03 \times 0.1 \mathrm{~mm}$. In the case of the polymer-modified bitumen, the range of softening points is from $75.4^{\circ} \mathrm{C}$ to $86^{\circ}$
$\mathrm{C}$, and the range of penetration is from 54.6 to $74.3 \times 0.1 \mathrm{~mm}$. The results are within the prescribed limits defined in the specifications for bitumen. Influence of bitumen composition on empirical properties is more specifically described in the paper "Impact of bitumen composition on empirical properties” (Remišová and Holý, 2018). In research have been found intermediate dependencies have been discovered between binder penetration and aromatics content (correlation in range of 0.64 PG bitumen to 0.48 PMB bitumen), softening point and resins content (correlation in range of $0.785 \mathrm{PG}$ bitumen to 0.469 PMB bitumen), penetration and carbon content (correlation in range of $0.86 \mathrm{PG}$ bitumen to $0.76 \mathrm{PMB}$ bitumen), softening point and hydrogens content (correlation in range of $0.73 \mathrm{PG}$ bitumen to 0.999 PMB bitumen).

The VTS values were calculated according to the equation mentioned above. The dynamic viscosity measurement values (recorded by a Brookfield viscometer at 120,130,135,140,150,160,165,170, and $180^{\circ} \mathrm{C}$ ) were used for determining the VTS. The VTS values calculated for both the modified and paving grade bitumen are in Table 3. The modified bitumen has lower VTS values (from -1.081 to 1.199) compared to the paving grade bitumen (from -1.287 to 1.480 ).

Tab. 3 Values of the VTS for modified and paving grade bitumen

The value of the VTS (-)

$\begin{array}{ccccccc} & \text { A1 } & \text { A2 } & \text { A3 } & \text { A4 } & \text { A5 } & \text { A6 } \\ & -1.322 & -1.336 & -1.416 & -1.364 & -1.480 & -1.287 \\ \text { PMB 45/80-75 } & \text { M1 } & \text { M2 } & \text { M3 } & \text { M4 } & \text { M5 } & - \\ & -1.111 & -1.081 & -1.199 & -1.111 & -1.115 & -\end{array}$

Tab. 2 Measured values of the penetration and softening points

\begin{tabular}{|c|c|c|c|c|c|c|c|c|c|c|c|}
\hline \multirow{2}{*}{ Parameter } & \multicolumn{6}{|c|}{ Bitumen 50/70 } & \multicolumn{5}{|c|}{ Bitumen PMB 45/80-75 } \\
\hline & A1 & $\mathrm{A} 2$ & A3 & A4 & A5 & A6 & M1 & M2 & M3 & M4 & M5 \\
\hline Penetration (0.1 mm) & 64.1 & 63.8 & 62.8 & 61.0 & 70.0 & 54.3 & 54.3 & 54.6 & 74.3 & 60.5 & 51.6 \\
\hline Softening point $\left({ }^{\circ} \mathrm{C}\right)$ & 49.8 & 49.8 & 49.0 & 48.0 & 49.0 & 51.0 & 85.2 & 80.8 & 75.4 & 78.4 & 86.0 \\
\hline
\end{tabular}


Tab. 4 Linear dependencies between the VTS parameter and the elemental and group composition of bitumen

\begin{tabular}{|c|c|c|c|c|c|c|c|c|}
\hline \multirow{2}{*}{ Parameter } & \multicolumn{8}{|c|}{ Coefficient of determination $\mathbf{R}^{2}$} \\
\hline & Saturates & Aromatics & Resins & Asphaltenes & $\mathbf{C}$ & $\mathbf{H}$ & $\mathbf{N}$ & $\mathbf{S}$ \\
\hline Bitumen 50/70 & 0.482 & 0.368 & 0.605 & 0.150 & 0.469 & 0.881 & 0.215 & 0.565 \\
\hline Bitumen PMB 45/80-75 & 0.305 & 0.001 & 0.108 & 0.109 & 0.512 & 0.938 & 0.119 & 0.594 \\
\hline Parameter & \multicolumn{2}{|c|}{ Resins/Asphaltenes } & \multicolumn{2}{|c|}{ Aromatics/Asphaltenes } & \multicolumn{2}{|c|}{ Asphaltene index } & \multicolumn{2}{|c|}{$\mathbf{H} / \mathbf{C}$} \\
\hline Bitumen 50/70 & \multicolumn{2}{|c|}{0.280} & \multicolumn{2}{|c|}{0.478} & \multicolumn{2}{|c|}{0.781} & \multicolumn{2}{|c|}{0.674} \\
\hline Bitumen PMB 45/80-75 & \multicolumn{2}{|c|}{0.104} & \multicolumn{2}{|c|}{0.131} & \multicolumn{2}{|c|}{0.166} & \multicolumn{2}{|c|}{0.897} \\
\hline
\end{tabular}

In the following steps, the relationship between the VTS and the elemental respective group composition of the bitumen for a particular bitumen was studied. If a relationship exists, it is important to know how greatly the elemental versus group composition of the bitumen influences the VTS of the bitumen binders. The relation between the VTS and elemental composition and the group composition versus the empirical tests (softening point and penetration) is expressed by a linear function.

The regression dependences and penetration (Figure 4) of the VTS show a high value of the determination coefficient $\mathrm{R}^{2}$ for both types of bitumen, i.e., polymer-modified bitumen and paving grade bitumen. The values of reliability in the relation between the VTS and penetration are in a range from 0.624 (for paving grade bitumen) to a value of 0.799 (for the polymer-modified bitumen), which means a correlation in a range of 0.789 (paving grade bitumen) to 0.893 (polymer-modified bitumen). The relationship between the softening point and the VTS was also examined. However, the dependencies were small $\left(\mathrm{R}^{2}=0.386\right.$ for the $\mathrm{PGB}$ and $\mathrm{R}^{2}=0.359$ for the PMB).

The linear dependencies between the VTS and elemental and group composition determined of the bitumen are shown in Table 4.
The highest correlation dependencies are shown between the VTS and hydrogen content (Figure 5). The values of reliability in the relation between the VTS and hydrogen are in a range from 0.881 (for paving grade bitumen) to a value of 0.9383 (for polymer-modified bitumen), which means a correlation in a range of 0.968 (polymer-modified bitumen) to 0.938 (paving grade bitumen). These values of the correlation show that between the VTS and hydrogen, some dependence exists.

High dependencies can also be observed with the sulphur and resin content (the PG bitumen). In addition to the group and elemental analysis, the dependence of the most important combination of the individual parameters commonly used in foreign research was observed to examine whether there is any dependence between the VTS and the given ratios (e.g., a high $\mathrm{H} / \mathrm{C}$ ratio indicates the presence of straightchain compounds, whereas a low $\mathrm{H} / \mathrm{C}$ ratio is a good indication of the presence of polynuclear aromatic systems. Very high dependencies have been shown in the $\mathrm{H} / \mathrm{C}$ ratio for both types of bitumen $(0.674$ for the PGB and 0.897 for the PMB) and in the asphaltene index for the PG bitumen $\left(\mathrm{R}^{2}=0.781\right)$.

The results of the regression analysis of the bitumen's group composition and viscosity-temperature susceptibility are in Table 4.
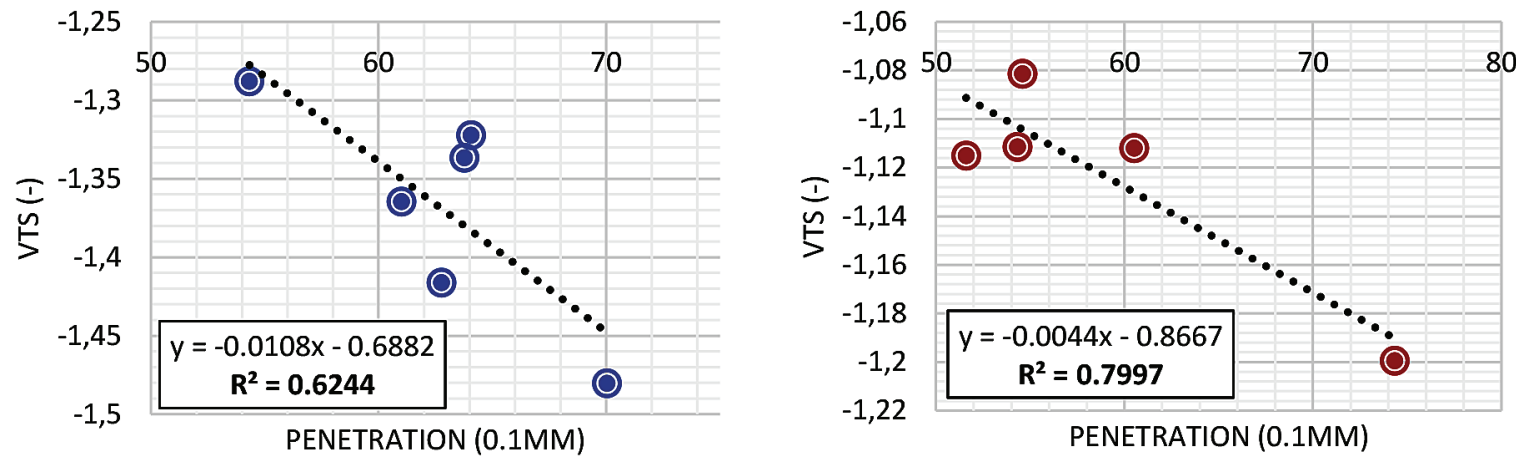

Fig. 5 Regression dependences between the VTS and penetration - PG bitumen (left), PMB bitumen (right)
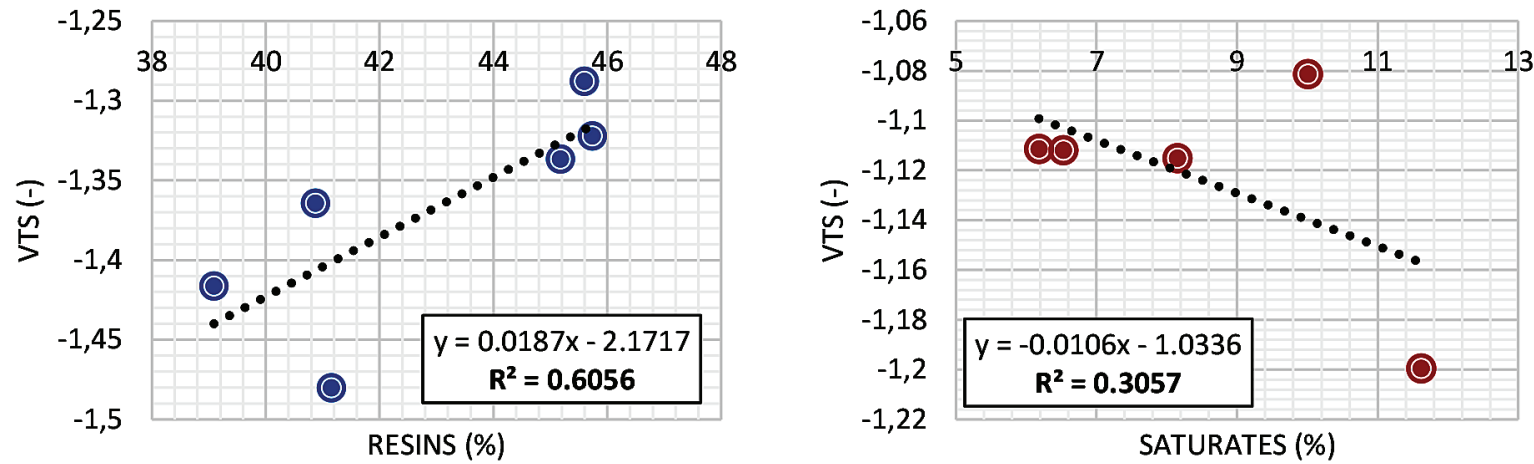

Fig. 6 Regression dependences between the VTS and hydrogen content of the PG bitumen (left), PMB bitumen (right) 
A relatively good level of regression was determined with the content of the saturates and resins (Figure 6). The values of reliability in the relation between the VTS and resins show a value of 0.605 (the PGB bitumen) and the values in the relation between the VTS and saturates show a value of 0.108 (the PMB bitumen), which means there is a correlation in a range of 0.777 (the PGB) to 0.522 (the PMB). These values of correlation show that between the VTS and resins, some dependence exists.

\section{CONCLUSIONS}

The quality of the bituminous binders used in the construction and maintenance of road surfaces is currently being assessed by empirical tests based on obtaining one value for specific boundary conditions. A characteristic feature of bitumen binders is that they change their consistency and properties with the temperature. The use of a viscosity-temperature susceptibility test that is influenced by the composition of the bitumen appears to be well-suited for an evaluation of the properties of bitumen binders. The goal of the presented paper was to determine the correlation between the VTS parameter and the physical properties and composition in the form of elemental and group compositions of unmodified and modified bitumen samples.

The values of reliability in the relation between the VTS and penetration are in a range from 0.624 (for the paving grade bitumen) to a value of 0.799 (for the polymer-modified bitumen). The relationship between the softening point and the VTS was also examined. However, the dependencies were only very small $\left(\mathrm{R}^{2}=0.386\right.$ for the PGB and $\mathrm{R}^{2}=0.359$ for the PMB). In addition to the group and elemental analyses, high dependencies were shown with the H/C ratio for both types of bitumen ( 0.674 for the PGB and 0.897 for the PMB) and with the asphaltenes index for the PG bitumen $\left(\mathrm{R}^{2}=0.781\right)$. In the case of the elemental composition, the values of reliability in the relation between the VTS and hydrogen content were in a range from 0.881 (the paving grade bitumen) to a value of 0.9383 (the polymer-modified bitumen). These values of the correlation indicate that between the VTS and hydrogen content, some dependence exists. Relatively good correlations were determined between the VTS and resin content with a value of reliability of 0.605 (for the paving grade bitumen) and between the VTS and saturates content with a value of 0.108 (for the polymer-modified bitumen). The results show that the VTS is not only dependent on viscosity but is also significantly dependent on the penetration and the group and elemental compositions.

\section{Acknowledgment}

The research was partially supported by the Scientific Grant Agency of the Ministry of Education, Science and Sport of the Slovak Republic and Slovak Academy of Science VEGA Grant No.1/0300/17 - Research of performance-related and rheological properties of bituminous binders. 


\section{REFERENCES}

ASTM D4402 (2016) Standard Practice for Viscosity-Temperature Chart for Asphalt Binders.

CSAB (2014) Catalog sheets of asphalt binders.

EN 12591 (2009) Bitumen and bituminous binders - Specifications for paving grade bitumen.

EN 14023 (2010) Bitumen and bituminous binders. Specification framework for polymer modified bitumens.

EN 1426 (2016) Bitumen and bituminous binders. Determination of needle penetration.

EN 1427 (2016) Bitumen and bituminous binders. Determination of the softening point. Ring and Ball method.

Mallick, R.B., El-Korchi, T. (2009) Pavement Engineering. Principles and Practise, CRC Press Taylor \& Francis Group. ISBN 978-1-4200-6029-4.

Kataware, A.V, Singh D. (2017) Evaluating effectiveness of WMA additives for SBS modified binder based on viscosity, Superpave $P G$, rutting and fatigue performance. Construction and building materials, Volume 146, August 2017, pp. 436-444. Available at: https://doi.org/10.1016/j.conbuildmat.2017.04.043

McLeod, N.W. (1989) Relationship of paving asphalt temperature susceptibility as measured by PVN to paving asphalt specifications, asphalt paving mixture design and asphalt pavement performance. Canadian Technical Asphalt Association, pp. 382-452.

Nicholls, J.C. (1998) Asphalt Surfacings - A guide to asphalt surfacings and treatments used for the surface course of road pavements. Transport Research Laboratory. ISBN 0-419-23110-2.
Peilong, L., et al (2018) Analysis of viscosity and composition properties for crumb rubbermodified asphalt. Volume 169, April 2018, pp. 638-647. Available at: https://doi.org/10.1016/j.conbuildmat.2018.02.174 (accessed at 05/03/2019).

Petersen, R.E. et al. (1994) Binder Characterization and Evaluation, Strategic Highway Research program. Washington. ISBN 0-309-05809-0.

Read J., Whiteoak D. (2003) The Shell Bitumen Handbook, 4th ed. Thomas Telford, London. ISBN 0-7277-3220-X.

Remišová, E., Holý M. (2018) Impact of bitumen composition on empirical properties. XXVII R-S-P Seminar, Theoretical Foundation of Civil Engineering, MATEC Web of Conferences, Vol. 196. Available at: https://doi.org/10.1051/matecconf/201819604038 (accessed at 05/03/2019).

Shafiq, H. (2016) Superpave asphalt binder specification. Available at: www. https://www.slideshare.net/hronaldo10/04superpave-binder-testing-highway-and-airport-engineering-dr-sherif-elbadawy (accessed at 22/01/2018).

VŠCHT (2017) Instructions for laboratory work of the Institute of Oil and Alternative Fuels, University of Chemistry and Technology Prague. Available at: http://utrap.vscht.cz/files/ uzel/0014520/0004 8zu8sCw_pVKhoChfIScxKb8osSS_KO wWqDA4YXJqQqHdxWXJJaVKhgZmgIA.pdf?redirected (accessed at 22/01/2018). 